\title{
Complicaciones del sistema nervioso central en triquinosis
}

\author{
Dra. Elizabeth Vega A. ${ }^{1}$; Dr. Gabriel Martinez D. ${ }^{2}$
}

Central nervous system complication in trichinosis

In two patients, 9 and 11 years old, with fever, palpebral edema muscle pain, symptoms meningeal irtitation reduced consciousness, ataxia, osteotendinous hyporeflexia and muscular hypertonus matket blood eosinophilia and normal cerebrominal fluid chemical and cytological findings, muscle biopsy confirmed the presence of trichinosis After treatment with thiabendazol and corticosteroids, total remission of symptoms and signs was obtained.

(Key words: Trichinella spiralis infection, encephalitis).

La triquinosis humana tiene en nuestro país, un carácter endémico con algunos esporádicos brotes epidémicos ${ }^{1-3}$. La ecología y epidemiología de esta parasitosis depende de una cadena compuesta por perros, gatos, ratas y cerdos. El hombre alimenta a perros y gatos con carnes crudas de diversos animales potencialmente in. fectados con Trichinella spiralis; los cadáveres de estas especies son eliminados a basurales donde son consumjdos por las ratas. Ratas, perros y gatos pueden ser ingeridos por el cerdo, el cual constituye el eslabón central de la transmitibilidad al hombre.

En gran porcentaje de los pacientes con

1. Becada Pediatría, Hospital Higueras, Talcahuano. Facultad de Medicina, Universidad de Concepción.

2. Jefe Unidad Segunda Infancia Hospital Higueras, Talcahuano. Prof. Adjunto de Pediatría, Facultad de Medicina, Universidad de Concepción. infecciớn triquinósica, ésta no se traduce en una enfermedad clínicamente reconocible o se con. funde con otras enfermedades infecciosas leves ${ }^{3}$. De las personas que presentan enfermedad clínica, una proporción no bien determinada sufre complicaciones neurológicas (10-24\%)

\section{Casos clínicos}

1. Niño de 9 años, eutrófico, de procedencia urbana, sin antecedentes claros de ingestión de carne de cerơo. Inició slus molestias cinco días antes de consultar, con sensación febril, edema facial y de extremidades inferiores. Al ingreso al servicio de quejaba de cefalea occipital y mialgias de las extremidades inferiores, astenia $y$ adinania; fiebre $\left(40^{\circ} \mathrm{C}\right)$ odinofagia, bradipsiquia, disartria y marcha atáxica. Al cuarto día de hospitalización aparecieron signos de irritación meníngez que persistieron durante 6 días. La fiebre cedió al noveno día de evolu. 
ción. A partir del séptimo dia de internado comenzó a recuperar paulatinamente la conciencia. El liquido cefalorraquídeo (LCR) fue normal en tres muestras; en el hemograma había leucocitosis de 11.800 por $\mathrm{mm}^{3}$, sin desviación a izquierda $y$ eosinofilia de $25 \%$; la VHS era de $7 \mathrm{~mm}$ en la primera hora. La biopsia muscular confirmó el diagnóstico de triquinosis. Fue tratado con tiabendazol durante 7 días, evolucionando favorablemente. Al ser dado de alta no presentaba secuelas neurológicas.

2. Varón de 12 años de edad, eutrófico, de procedencia rural. Sus molestias comenzaron tres semanas después de haber ingerido carne de cerdo faenado clandestinamente, con inapetencia, astenia, adinamia, edema bipalpebral, vómitos explosivos y discretas mialgias de las extremidades inferiores. Se hospitalizó siete dias más tarde; sudoroso, pálido, febril (hasta $40^{\circ} \mathrm{C}$ ); edema palpebral $y$ hemorragia subconjuntival bilateraks. Evolucionó con bradipsiquia, bradilalia, obnulación, desconección ambiental durante varias horas, signos de irritación meníngea, hipertonía e hiperreflexia de extremidades inferiores. El examen del LCR estaba dentro de límites normales; en el hemograma había leucocitosis de 18.000 por $\mathrm{mm}^{3}$, desviación a izquierda de $31 \%$, eosinofilja de $22 \%$; la VHS era de $7 \mathrm{~mm}$ la primera hora. En el fondo de ojo no se encontraron alteraciones. Se realizó tratamiento con corticoides y tiabendazol, recuperando la conciencia en 12 horas, persistiendo las mialgias de extremidades inferiores y dorsalgias discretas durante 5 días. En la biopsia muscular se encontró evidencia de triquinosis.

\section{COMENTARIO}

La triquinosis humana, manifiesta clinicamente, es poco frecuente en nuestro medio $^{1,3}$. La incidencia, segin los anuarios de enfermedades de notificación obligatoria (1979-1983) y el censo nacional de pobla. ción (1982), es de 1,1 por 100.000 habitantes, con $1,5 \%$ de letalidad ${ }^{3}$.

Estudios hechos en Santiago de Chile demostraron $2,8 \%$ de casos de infestación triquinósica en personas que murieron violentamente $y$ que estaban aparentemente sanas $^{3}$ lo cual significa que existe gran cantidad de infecciones subclínicas. La letalidad de esta enfermedad, sube abruptamente cuando compromete al sistema nervioso central desde alrededor de $1,5 \%$ a 8 o $46 \%$ 5-8. De to que se deduce la importancia que tienen el diag. nóstico y tratamiento oportunos de esta com.. plicación. Los signos de infección del sistema nervioso se hacen evidentes en la fase de $\mathrm{mi}$ gración de la larva o invasión hística, que comienza al final de la segunda semana de la enfermedad y persiste durante cuatro sema. nas. Como las larvas no tienen predilección por determinados territorios deI sistema nervioso central, llegan a él sin ningung sistematización ${ }^{4}$, al azar, to que explica to polimorfo de los sintomas y signos del compromiso neurológico: así, se describe como manifestaciones de las complicaciones neurológicas, desorientación, delitio, encefalitis, meningitis, psicosis, of talmoplegias, afasias, mono plegias, hemiplegias, paraplegias, tetraplegias, sindromes cerebelosos, etc. ${ }^{4,5,7}$ En el cerebro las larvas de triquinosis no se enquistan debido a su escaso tejido conectivo ${ }^{4.9}$ y su destirio es ser destruidas o pasar a ot ros territorios como el LCR $^{7}$ : Por esta razón, las lesiones histopatologicas de este 6 rgano no se pueden explicar por la presencia in situ de la larva, invocándose una serie de mecanismos teóricas immunológicos, de hipersensibilidad, tóxicos 4.5 y obstrucción de arteriolas y capilares por la pasada transitoria del parásito por estas estructuras para explicarlas. La teoría alérgica ha sido supuestamente avalada por la existencia de casos con buena respuesta a los corticoides $^{4,6-6}$. Los hallazgos anatomopatoló. gicos más frecuentes han sido: meninges y cerebro edematoso e hiperémicos, hemorragias puntiformes en estructuras subcorticales y en la base de1 cerebro, nódulos granulomatosos, infiltrados perivasculares en arteriolas y venas y larvas 4-7. Histológicamente se ha observado hiperhemia, profileración endotelial e infiltración con linfocitos de las meninges y el cerebro ${ }^{4}$.

Dentro de los exámenes de laboratorio, desta. ca la eosinofilia, que aparece en los primeros diez días de la infección. alcanzando 10 a $40 \%$ de los leucocitos 6,7 : No está claro si su magnitud tiene relación con la gravedad de la enfermedad. Se ha descrito casos fatales que presentaban aneosinofilia ${ }^{6-8}$. El recuento de leucocitos suele estar normal o moderadamente elevado y la velocidad de sedimentación de los glóbulos rojos (VHS) es normal e incluso baja. 
El LCR en 50 a $75 \%$ de los casos es normal ${ }^{5-8}$, en el resto se han observado pleocitosis, presión elevada, xantocromia, aumento de las proteínas, cambios en el nivel de glucosa ${ }^{8}$. En algunos casos se han identificado larvas en el LCR $^{7,8}$. El electroencefalograma muestra evidencia de encefalopatía difusa y la tomografia axial computarizada opacidad de los hemisferios cerebrales 5 .

Algunos métodos utilizados para el diagnóstico son la prueba intradérmica con antígenos de larvas de trichinella; las pruebas de fijación del complemento, las pruebas de precipitación y la prueba de floculación de bentonina. Todas son positivas desde la segunda a cuarta semana de enfermedad y pueden dar falsos positivos o negativos. La biopsia museular, donde se encuentra la larva encapsulada no calcificada rodeada por células inflamatorias, confirma el diagnóstico. En nuestros dos casos se realizó biopsia muscular y en el primero fue fundamental para el diagnóstico.

Las triquinosis Icves sólo deben tratarse sintomáticamente ${ }^{10.11}$. En cambio en las masivas o con complicaciones neurológicas o cardíaca debe administrarse un antihelmintico (tiabendazol o meberrdazol) y corticoides en dosis eleva. das 10.12 .

En los casos relatados se usó tiabendazol en dosis de $50 \mathrm{mg} x \mathrm{~kg}$ de peso durante 7 y 10 días e hidrocortisona $10 \mathrm{mg} \times \mathrm{kg}$ de peso, obteniéndose espectacular regresión de los s̀íntomas neurológicos en el segundo caso, tal como ha sido descrito por otros autores $5,7,8$.

Conviene subrayar que esta enfermedad es poco frecuente en pediatria y generalmente es difícil de diagnosticar; se puede confundir con otras afecciones como fiebre tifoidea o encefalit is viral, especialmente si no se tienen claros antecedentes de ingestión de came de cerdo.

\section{RESUMEN}

Se presentaron dos pacientes de 9 y 11 años de edad, con cuadros clínicos similares consistentes en un sindrome febril de causa inaparente, edema palpebral, mialgias y compromiso encefálico importante. El hemograma demostró una cosinofilia marcada $y$ el estudio del liquido cefalorraquídeo fue normal. En ambos la biopsia muscular confirmó el diagnóstico de triquinosis. Tratados con tiabendazol y corticoides, hacen una evolución favorable con regresión de la sintomatologia.

\section{REFERENCIA}

1. Schentone H., Szekel R., Ramirez R., Rojas A.. Aspectos cpidemiológicos de la triquinosis humana en Chile. Bol Chil l'arasitol 27: 103, 1972.

2. Cabrera G., Pintlk N, Dallorse L., Parra G.: Brote cpidemiológico de triquinosis en Concepción. Bol Chil Parasitol 37: 47, 1982.

3. Schenone H., Sandonal L.., Contreras M., Saavedra $T$., Letorjo $T$.: Actualización y perkpectivas sobre la epidemiolouia de la triquinosis en Chile. Bol Chil Parasito1 38: 63, 1983.

4. Gay T., Fatal C.N.S.: Trichmosis. JAMA 247: 1024, 1982

5. Lyen-Caen O.. Haw y cols. La trichinose du Systeme Nerveux Central. N. Presse Medicale ll: $2343,1982$.

6. David J.: Trichinosis: Severe myopathic involvement with. Neurology 26:37, 1976.

7. Dalessio J.: Trichinella spiralis infection of the central nervous system Arch licurol 4: 507, 1961.

8. Morton D., Kramer M.D., Atte J.: Trichinosis with central nervous system involvement. Neurology 22 $485,1972$.

9. Gray D.: Trichinosis with neurologic and cardiac involvement. Ann Intern Med 57: 230, 1962,

10. Kean $I$. , Foskins $W$.: Tteatment of trichinosis with Thiabendazole. JAMA 190: 116, 1964.

11. Goodman y Gilmon: Las bases farmacológicas de la terapéutica. 7a. ed. Buenos Aìres, lidítorial Panamericana, 1986; 962-978.

12. Keyston S.: Mcbendazolc. Ann Intern Med. 91: $582,1979$. 